\title{
Investigación de mercados para export- ación de joyas en plata, a Estados Unidos
}

\author{
Por: Johanna Acero Enríquez \\ Corporación Universitaria Minuto de Dios
}

\section{Introducción}

En Colombia, la minería de plata está ligada esencialmente con la producción de oro de filón. No existe en el país una compañía que tenga como único propósito su producción.

El total de la producción de plata del país es de aproximadamente 7 toneladas/año.

En el año 2001, los principales departamentos productores fueron:

\section{Resumen}

En la actualidad, un estudio de mercado constituye uno de los campos más importantes para llevar a cabo un proyecto, empezar un negocio, crear una empresa entre otros. Aunque muchas personas optan por empezar un negocio de forma instantánea, en la mayoría de los casos se logran concretar negocios que estimulan el espíritu empresarial pero carecen de base, que permita un buen sostenimiento futuro.

Para conocer la factibilidad de exportar joyas en plata a Estados Unidos, de fabricación colombiana, se realizó un estudio previo y profundo de la idea, para luego poderla poner en marcha conociendo las tendencias y gustos del mercado estadounidense.

Se puede dar una estructura de cualquier organización, para así facilitar la labor comercial y logística del negocio, de esta forma desarrollar una excelente exportación, ya que este plan es apoyado por la investigación de mercados efectuados, teniendo como base primordial las posibles estrategias de mercados, procesos de producción, distribución y conocimiento general sobre el producto a exportar, permite establecer condiciones óptimas para llevar a cabo una exportación.
Antioquia con $59 \%$, Córdoba $19 \%$, Caldas $16 \%$ y Bolívar $2 \%$, que representan el $96 \%$ del total nacional. La joyería colombiana utiliza alrededor de 1.4 toneladas/año, equivalente al $20 \%$, lo que demuestra que existe la suficiente disponibilidad de esta materia prima.

En lo referente a la demanda mundial de plata, esta ha sido creciente en los últimos 15 años, con excepción de 1998, cuando decreció ligeramente y volvió a incrementarse en el período 1999 - 2000, en más del $5 \%$ logrando una cifra record de 28.642 toneladas. Los tres grandes componentes de la demanda aún son la fotografía, joyería y artesanías en plata.

En cuanto al precio del metal en el país, éste ha estado ligado directamente con la cotización internacional. Colombia debe entrar al mercado ofreciendo joyas con diseños de vanguardia, a precios competitivos. El presente estudio de mercado tiene como objetivo proporcionar al exportador colombiano de joyería la información necesaria para conocer las exigencias del mercado, el carácter de la competencia, los factores determinantes de la demanda de estos productos, y las condiciones de acceso.

Se presenta también un análisis del potencial para los siguientes productos:

joyería fina y bisutería, y recomendaciones clave para introducir dichos artículos exitosamente en Estados Unidos. 
Este estudio fue realizado considerando las fuentes de información más recientes disponibles a la fecha de elaboración. La información primaria fue obtenida fundamentalmente a través de entrevistas con asociaciones de joyeros, editores de revistas de joyas, importadores, manufactureros, tiendas especializadas en joyería y tiendas por departamento que también ofrecen estos productos, de igual manera se obtuvo información en visitas a los diferentes puntos de venta. La información secundaria, por su parte, fue obtenida de fuentes diversas, publicaciones del sector, entidades gubernamentales, asociaciones, empresas (brochures, memorias y documentos emitidos por estas entidades).

\section{Metodología}

\section{Información generall}

Estados Unidos cuenta con empresas dedicadas a la elaboración de joyas y artículos de joyería, pero depende a su vez de proveedores internacionales para suplir la demanda interna, sobre todo para joyería de precios más bajos donde la mano de obra estadounidense encarece el producto.

El sector de joyería fina representa ventas significativas del orden de 1.2 billones de dólares anuales siendo el diamante la piedra preciosa más importante y apreciada por el consumidor de dicho país.

El sector de joyería ha crecido en los últimos años y el consumidor estadounidense se reconoce como un comprador importante de estos artículos, sobre todo en lo que respecta a anillos de compromiso, donde la tasa de compra anual es más alta que el promedio de los demás países desarrollados.

\section{Estudio de mercado y localización de la demanda potenciall}

La exportación requiere inicialmente de una selección de mercados, donde se determinen las características específicas del país donde se quiere exportar: identificación de posibles canales de distribución, precio de la exportación, hábitos y preferencias de los consumidores en el país o región, requisitos de ingreso, vistos buenos, impuestos, preferencias arancelarias y otros factores que están involucrados en el proceso de venta en el exterior.

Entendiendo como mercado potencial aquellos clientes que compran joyas en plata colombianas, sin importar la existencia de la competencia, dentro de este grupo se encuentran las personas que de una u otra manera han utilizado la joyería colombia- na ya que esta tiene gran variación de diseños y son autóctonos de nuestra tierra, y que están satisfechos por la originalidad de los nuestros productos.

Población. Los elementos a encuestar son las personas que viven en Nueva Jersey y que utilizan joyas en plata, en síntesis son todos aquellos que cumplen con la segmentación escogida; ya que en Nueva Jersey existe una población de 8.143.412 de habitantes, con base en el censo realizado en el 2005 se obtuvo como resultado que el $45 \%$ de la población son mujeres en síntesis son 3.664.535 millones, el total de la población mas interesada en el producto son las mujeres de 39 a 45 años que en este caso corresponde al 30\% son 1.099.360 millones; aproximado da 1.100.000 personas; es nuestra población seleccionada, también nuestra población la comprenden los 20 (veinte) distribuidores del producto en EE.UU. de donde sale como resultado la segunda muestra.

Unidad de muestreo. Esta comprende parte del estado de Nueva Jersey.

Alcance. La cobertura de la encuesta se encuentra en el estado de Nueva Jersey. Tiempo. El tiempo para realizar esta encuesta fue de 2 (DOS) mes septiembre y octubre de 2007.

Marco muestral. Es el listado donde encontramos la referenciada población; según la oficina encargada de los datos estadísticos, Boreal of labor statistics.

\section{Cállculo del tamaño de la muestra* para los consumidores}

Población infinita: la población se pasa de 100.000 personas por el estado investigado. $\mathrm{N}$ = Población: 1. 100.000 tamaño de la población consumidores en estudio $Z=$ Nivel de confiabilidad $95 \%=(1.96 \%)$ según tabla de distribución de frecuencia.

$E=$ Nivel de error $=5 \%=0.05$

$\mathrm{S} 2=\mathrm{P} \times \mathrm{Q}$

$P=192=50 \%(0.5)$ igual proporción

de probabilidad de éxito $(P)$

$Q=192=50 \%(0.5)$ igual proporción

de probabilidad de fracaso $(Q$ Por ser

población infinita

Fórmula (utilizando muestreo aleatorio simple)

$\mathrm{n}=\mathrm{Z2} \times \mathbf{P} \times \mathbf{Q}$

E2

$\mathrm{n}=(1.96) 2(0.5)(0.5)$

$(0.05) 2$

$\mathrm{n}=0.9604$

0.0025

$n=384$ encuestas a consumidores.

* Para los distribuidores 
Población finita: corresponden a 20 distribuidores en Nueva Jersey. N: Población (20 distribuidores). Para los distribuidores en el estado de Nueva Jersey; por ser una pequeña población se optó por hacerle un censo a los 20 distribuidores con las preguntas.

\section{Desarrollo del tema}

Las oportunidades que ofrece este sector para la empresa colombiana se relaciona con el proceso de modernización del sector que requiere cada día de nuevos procesos y tecnologías. Se destaca la implementación de un software para el diseño de joyas, el uso de herramientas y la importación de piedras preciosas como las perlas en cristal para las bisuterías. El mercado colombiano necesita un inversor que apoye y genere tendencias de diseños alternativos y modernos junto con maquinaria adecuada para producir en Colombia y exportar a los mercados internacionales. En Colombia, hay mano de obra calificada y diversificación de talleres los cuales pueden ser utilizados para

producción masiva. En el caso de Colombia, que avanza en las negociaciones del ALCA y se trabaja bajo el enfoque de cadenas productivas una política para la industria de la joyería se convierte en una necesidad, toda vez que el Acuerdo de Libre Comercio puede representar oportunidades como desafíos para el país, porque ello significa, en términos de mercado, 800 millones de habitantes, es decir el 13.4\% de la población mundial, US\$ 10.000 millar dos de PIB y más del $20 \%$ del comercio global. (Fuente Estudios).

\subsection{Segmento del mercado potencial, grupo de}

35 a 49. Este grupo es considerado como el más importante en el consumo de joyas finas, con una participación aproximada del 30\%. Sus compras generalmente son mayores de US\$350 dólares. Sus preferencias son los brazaletes, aretes, anillos y collares fabricados en oro con o sin incrustaciones en piedras preciosas. Es el grupo más susceptible a la compra de joyas con diferentes piedras preciosas, un promedio del $40 \%$ se interesa por piedras preciosas diferentes al diamante.

3.2 Características del producto. Las joyas a producir son pendientes, dijes y argollas, unas de ellas serán diseñadas solamente en plata y otras se combinarán con piedras montadas en sus diferentes formas (engaste, bicel y sistema de uñas). Como características generales encontramos que los colores varían entre plata y combinaciones de cáscara de coco, nueces, y piedras en general a nivel semillas naturales.

\section{Dije en plata}

\subsection{Empaque del producto}

La forma de presentación será individual empacados en bolsitas de celofán con el fin de visualizarlas, protegerlas y que su empaque perdure. Cada joya llevará un tiquete en el cual se inscribirá el logotipo, referencia del modelo. En cuanto a: las joyas se empacarán de manera individual (la distribución de los demás joyeros no tienen este método y es muy favorable ya que disminuye el mal trato).

\subsection{Análisis de la distribución física}

La logística de transporte para joyas desde Colombia se concentra en los envíos aéreos dadas las características de la carga. Muchos de los importadores estadounidenses, afirmaron que para mayor seguridad es mejor utilizar los servicios de Federal Express y DHL para realizar sus importaciones, debido a la cantidad y el valor de la mercancía transportada. También para joyas de un valor muy elevado el proveedor de transporte escogido es Brinks.

Según datos obtenidos, por medio del servicio al cliente de DHL y Federal Express, se encontró que la cantidad máxima asegurada es de US\$500 dólares, si el exportador desea enviar mercancías de mayor valor debe ocuparse él mismo del seguro adicional de los productos, además de contratar el broker para el proceso de nacionalización en Estados Unidos.

\subsection{Análisis general}

1. La clave de éxito en el desarrollo del mercado estadounidense está en una organizada estrategia de mercadeo. Dentro de los aspectos que requieren especial atención se encuentran: a. Intercambio de muestras dentro del menor tiempo requerido, de calidad y precio atractivo, ello asegurará al comprador que el exportador es una alternativa viable. b. Respuesta inmediata a cualquier comunicación recibida (por correo electrónico, fax o teléfono). Un importador que no puede comunicarse fácilmente en inglés con un proveedor, cambiará rápidamente a otro. c. Despachos a tiempo, en caso de demoras se debe explicar al importador la causa de las mismas.

La primera impresión es muy importante para la mayoría de los compradores. Por ello, juega un papel importante la información inicial de la empresa y sus productos, incluyendo fotografías y/o página electrónica y catálogos (en inglés y francés, este último especialmente para el mercado de la provincia de Québec), las muestras y un dominio total de los productos que desea vender, su estructura de costo y producción, con precios definidos (FOB y CIF). La puntualidad es muy respetada e importante. 
El ambiente de negocios es relativamente informal donde el protocolo es mínimo.

En Estados Unidos todo se programa con mucho tiempo de anticipación, por lo que se puede encontrar que los mejores hoteles y lugares para eventos ya están ocupados.

De igual manera los importadores hacen sus compras con mucha antelación a las temporadas de venta para poder distribuir a tiempo los productos.

\section{Conclusiones}

Los usuarios de joyas en plata en el estado de Nueva Jersey tienen, como prioridad, al momento de comprar una joya la calidad; ya que esta es la que da a conocer la durabilidad elegancia y vida útil del producto.

Con esta investigación se dio a conocer que, sin duda alguna, los usuarios recomiendan el producto ya que este es innovador, de buena calidad y que cuenta con creatividad en el diseño. El producto puede ser utilizado por todo tipo de personas, sin discriminar edades clases sociales, estratos pues este es el producto que se adapta a cualquier individuo.

\section{Referencia bibliográfica}

Bernal Torres, César Augusto. 2000. Metodología de la Investigación para Administración y Economía, Pearson, Santafé de Bogotá.

Contreras Buitrago, Marco Elías. 1998. Formulación y Evaluación de Proyectos, Unad, Santafé de Bogotá.

Miranda Miranda, Juan José. 1998. Gestión de Proyectos, Guadalupe, Santafé de Bogotá, tercera edición.

-http://www.aajewelers.com/index.html joyas en EE.UU.

•nttp://www.info@proexport.com.co

\section{Glosario}

\section{Acuerdo bilateral}

Un acuerdo suscrito entre dos partes que liberaliza el intercambio de bienes, servicios e inversiones. Para ello se establece un marco regulador que rige a las partes y que permite, entre otros beneficios, eliminar impuestos aduaneros en forma total o gradual en el tiempo

\section{OMC}

La Organización Mundial de Comercio, con sede en Ginebra (Suiza), es el principal organismo internacional que se ocupa de las normas que rigen el comercio entre los países, y cuenta en la actualidad con 146 miembros.

\section{INCOTERMS}

La finalidad de los INCOTERMS, creados por la Cámara de Comercio Internacional, es establecer un conjunto de reglas internacionales para la interpretación de los términos más utilizados en el comercio mundial.

\section{Bisutería}

Trabajo de producción de alhajas y objetos decorativos con la tecnología de la joyería, pero se distingue por el tipo de materiales utilizados, tales como el peltre, de distintas clases según las aleaciones, cobre, bronce, zinc, níquel, cobalto, aluminio, antimonio, hierro. Complementan con engaste de piedras de camafeo, piedras semipreciosas. El equipo de trabajo como máquinas y herramientas es prácticamente el mismo de la joyería, cuando la producción es de alta calidad

\section{Joyería}

Es el oficio artesanal representado en prendas ornamentales llevadas en el cuerpo, que generalmente se fabrican con metales preciosos o semipreciosos y piedras, aunque también se pueden emplear materiales de menor valor. 